\title{
PVDF-PAni blend: a free-standing film with variable electrical resistance
}

\author{
E. A. Sousa ${ }^{1}$ - W. D. S. Deniz ${ }^{1}$ - E. P. S. Arlindo ${ }^{1}$ • \\ W. K. Sakamoto ${ }^{2}$ G. C. Fuzari Jr ${ }^{1}$
}

Received: 30 June 2015/Revised: 1 August 2016/ Accepted: 11 August 2016/

Published online: 16 August 2016

(C) Springer-Verlag Berlin Heidelberg 2016

\begin{abstract}
Films made of a blend of polyaniline (PAni) and a nonpolar polyvinylidene fluoride (PVDF) polymer matrix were obtained by the mechanical mixing of both, with subsequent melting and quenching. Using the current versus voltage $(\mathrm{IxV})$ measurements, the percolation threshold (concentration in which some conducting particles are connected to form at least one conductor path, related to one direction of the film) was determined to be between 40 and $45 \%$ in volume along the surface. Related to the film thickness, a small amount of PAni $(0.5 \%$ in volume) was enough to transform the blend in a conducting material. Strain-stress tests indicated that a small amount of PAni can reinforce the polymer matrix. Furthermore, the immiscible blend obtained changes in its electrical conductivity, according to the $\mathrm{pH}$ of the solution in which it was immersed, indicating the possibility of the real application of that material as a resistor with variable electrical resistance.
\end{abstract}

Keywords Electrical conductivity $\cdot$ Mechanical properties $\cdot$ Blend films

\section{Introduction}

Nowadays, processing materials with different phases that combine the better properties of each individual phase is increasingly common in industries seeking the welfare of the population. In general, polymeric material has excellent mechanical

G. C. Fuzari Jr

gcfjunior@yahoo.com.br

1 Instituto de Ciências Exatas e da Terra, Universidade Federal de Mato Grosso, Barra Do Garças, MT CEP 78600-00, Brazil

2 Departamento de Física e Química, Universidade Estadual Paulista, Ilha Solteira, SP CEP 15385-000, Brazil 
properties, easy processing, and allows mixing with conducting or semiconducting materials, generating a new material, called a composite or blend, with new properties $[1,2]$.

In this context, in the study of this new material, it is important to define the percolation threshold, so that it can have at least one path for the electrical charge flow [3]. This allows some applications of this material, such as antistatic packaging. The advantage of the use of polyaniline (PAni) instead of conductor particles, like carbon black, is the control of the electrical conductivity of the PAni by protonation/deprotonation, through the control of the $\mathrm{pH}$ of the organic or aqueous solution [4]. Polyvinylidene fluoride (PVDF) was chosen as a polymer matrix, due to its excellent mechanical properties, and because it can be processed without an organic solvent, since it is a crystalline thermoplastic [5, 6].

There are several good research studies showing that PAni can be used to prepare blends or composites, mainly because it is $\mathrm{pH}$ sensitive. However, the effect of the change in $\mathrm{pH}$ was exploited before or during the sample fabrication, while the samples were studied for application as a sensor, and they were mounted over the substrate; generally, the films were self-assembled, layer by layer [7, 8]. The aim of the present work was to obtain free standing PVDF-PAni flexible films, over the percolation threshold, in which the electrical conductivity can be changed even after its fabrication, according to its specific application. Sensors, resistors and capacitors can be built in a single piece with size, shape and electrical conductivity is wanted. In addition to its electrical and mechanical characterizations, some properties related to the morphology of the material will be discussed.

\section{Materials and methods}

\section{Blend components}

Nonpolar PVDF ( $\alpha$ PVDF) powder, Solef 1008/1001 from Solvay Fluoropolymers, with a $1.78 \mathrm{~g} / \mathrm{cm}^{3}$ density was used. The PAni was obtained following the method proposed by MacDiarmid [4], polymerizing the aniline $\left(\mathrm{C}_{6} \mathrm{H}_{5} \mathrm{NH}_{2}\right.$; Sigma Aldrich), $99 \%$ pure in the presence of ammonium peroxydisulfate $\left[\left(\mathrm{NH}_{4}\right)_{2} \mathrm{~S}_{2} \mathrm{O}_{8}\right.$; Merck], in an aqueous solution of hydrochloric acid $(\mathrm{HCl})$ at $1.0 \mathrm{M}$, under constant stirring with a temperature below $4{ }^{\circ} \mathrm{C}$. The PAni obtained was washed with a $0.1 \mathrm{M} \mathrm{HCl}$ solution, and dried in an oven at $50{ }^{\circ} \mathrm{C}$. The doped PAni (emeraldine phase) with a $1.30 \mathrm{~g} / \mathrm{cm}^{3}$ density was macerated for grain separation.

\section{Obtaining blends}

The components were mechanically mixed in the desired proportions. In the powder form, both the PVDF and PAni were put between Kapton sheets (polyamide), and hot pressed at $185^{\circ} \mathrm{C}$ for $2 \mathrm{~min}$ at 7.0 $\mathrm{MPa}$, using a Marconi MA 098/A hydraulic press. The blended films were obtained with thicknesses in the range of 70-320 $\mu \mathrm{m}$. 


\section{Solution preparation for composite electrical conductivity control}

To control the electrical conductivity of the PVDF-PAni blend, the sample was dedoped by immersing it for $24 \mathrm{~h}$ in a $0.1 \mathrm{M}$ ammonium hydroxide $\left(\mathrm{NH}_{4} \mathrm{OH}\right)$ solution, at a $\mathrm{pH}$ of 10-11. After that, the dedoped sample was redoped using a $0.0001 \mathrm{M} \mathrm{HCl}$ solution, with a $\mathrm{pH}$ of between 3.05 and 3.10, and monitored with an mPA210 pH meter (MS Tecnopon). According to the desired re-protonation degree, the sample was immersed in a different volume of $0.0001 \mathrm{M} \mathrm{HCl}$ solution. The advantage of using a different volume of the $\mathrm{HCl}$ solution with a fixed concentration, instead of varying the concentration, is the possibility of using just one pattern solution, which can be very dilute. The volume of the solution necessary for PAni protonation was calculated using the mass of the blend with a $47 \%$ volume of PAni, for which the molecular mass is $220,000 \mathrm{~g} / \mathrm{mol}$ [9].

\section{Fourier transform infrared spectroscopy (FT-IR)}

A spectrum 100 spectrometer (Perkin Elmer) with an ATR device, germanium window, range analysis of $4000-600 \mathrm{~cm}^{-1}$, and $4 \mathrm{~cm}^{-1}$ resolution was used. The equipment was controlled using EZ OMNIC software. The samples used were PVDF and PAni powder, and the PVDF-PAni blend film.

\section{Optical microscopy image}

An Olympus BX-51 binocular microscope was used with an Olympus DP72 camera.

\section{Electrical conductivity measurement}

The measurements were carried out using a Keythley model 2611 SourceMeter on the surface (conductance measurement $-I / V$ rate) and across the thickness (volume), using the following equation:

$$
\sigma=\frac{I}{V} \frac{L}{A}
$$

where $I, V, L$, and $A$ are the electrical current, electrical voltage, thickness, and electrode area, respectively.

\section{Stress-strain tests}

The analyses were performed in a model WDW-300 E universal testing machine at room temperature, $12.5 \mathrm{~mm} / \mathrm{min}$ deformation velocity, and a load cell of $150 \mathrm{kN}$, according to the ASTMD1708-10 standard. 


\section{Results and discussion}

Infrared spectroscopy with Fourier transform was used to verify the possible chemical reactions between the components of the blend. Figure 1 shows the band related to the characteristic bonds of the deprotonated PAni, which is stated in detail in Table $1[10,11]$. In a similar way, the chemical bonds related to the PVDF are shown in Table 2. The obtained spectra are in agreement with those shown in the literature [10-12].

It is easy to see that the bands related to the PVDF characteristic bond are keep intact in the PVDF-PAni blend, with 47 vol\%, which means the components of the blend are immiscible. Consequently, it is possible to observe, through optical microscopy, two phases: PAni and PVDF of different sized conductor phases in the sample. Figure 2 shows the different sizes of the agglomerated particles of the PAni forming films with non-uniform distribution.

Despite these localized regions, in general, it is possible to observe the homogeneity of the films. With increasing PAni concentrations, the blend film becomes thick and fragile. For blends with 47 vol\% of PAni, the particles are already connected, as shown in Fig. 3. The percolation threshold is reached close to this concentration, and the inset in Fig. 3 shows the possible path for the electrical charge conduction.

The sudden increase in the conductance can be observed in the $\mathrm{I} \times \mathrm{V}$ measurement along the surface of the sample, in the range of 40-50 vol\% of PAni, as shown in Fig. 4. The high percolation threshold must be due the preparation of Pani in $\mathrm{HCl}$ solution that constitutes large agglomerates and their subsequent insertion into the molten matrix. Unlike other methods, in this case, the PAni is not dissolved with the organic acids or prepared in situ during the composite fabrication [13-15]. The advantage is that it is a relatively simple method of processing and very low cost, which allows the creation of a flexible material that once done can be altered electrical resistance.

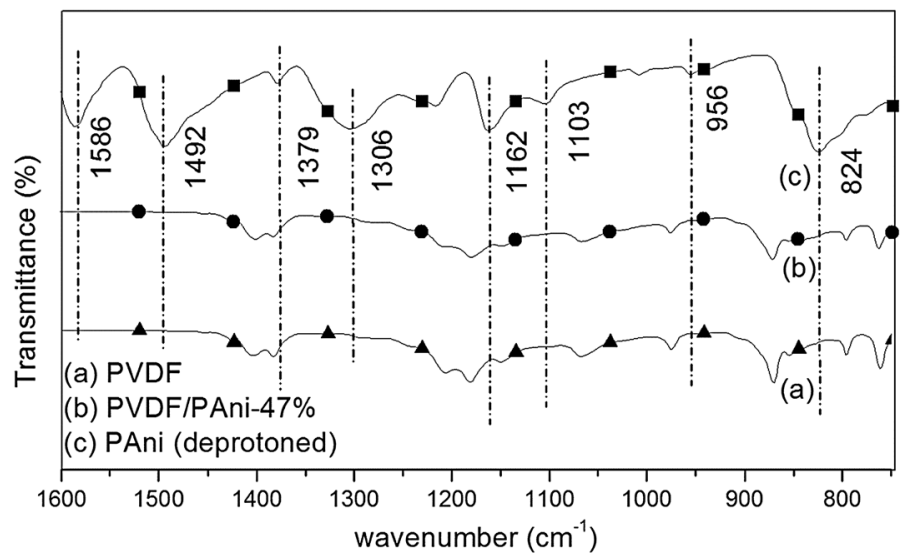

Fig. 1 FT-IR of PVDF/PAni blend films 
Table 1 Frequencies/ assignments: bands of FTIR spectra for PAni $(10,11)$ ip in plan, $o p$ out of plan, $B$ benzenoid ring, $Q$ quinoid ring, arom aromatics

\begin{tabular}{lll}
\hline Experimental & Literature & Attribution \\
\hline 1586 & 1587 & $\mathrm{~N}=\mathrm{Q}=\mathrm{N}$ str. \\
1492 & 1510 & $\mathrm{~N}-\mathrm{B}-\mathrm{N}$ str. \\
1379,1306 & 1380,1315 & str. $(\mathrm{C}-\mathrm{N}$ ) of aromatic amines \\
1162 & 1160 & $\mathrm{~N}=\mathrm{Q}=\mathrm{N}$ absorption \\
1103 & 1105 & $\mathrm{C}-\mathrm{H}$ of aromatic ring. 1,4 ip \\
956 & 960 & $\mathrm{C}-\mathrm{H}$ of aromatic ring $1,2,4$ ip \\
824 & 830 & $\mathrm{C}-\mathrm{H}$ of aromatic ring. 1,4 op \\
\hline
\end{tabular}

Table 2 Frequencies/assignments: bands of FTIR spectra for PVDF [12]

\begin{tabular}{lll}
\hline Experimental & Literature & Attribution \\
\hline 1404 & 1434 & bending $\left(\mathrm{CH}_{2}\right)$ \\
1384 & 1398 & wag. $\left(\mathrm{CF}_{2}\right)+$ str. asym. $(\mathrm{CC})$ \\
1179 & 1185 & bend. $(\mathrm{CCC})+$ str. sym. $\left(\mathrm{CF}_{2}\right)+$ str. $(\mathrm{CC})$ \\
1066 & 1063 & str. $(\mathrm{CC})+$ wag. $\left(\mathrm{CH}_{2}\right)+$ wag. $\left(\mathrm{CF}_{2}\right)$ \\
973 & 991 & tw. $\left(\mathrm{CH}_{2}\right)$ \\
871 & 886 & stretching asym. $\left(\mathrm{CF}_{2}\right)$ \\
853 & 843 & rock. $\left(\mathrm{CH}_{2}\right)+$ str. sym. $\left(\mathrm{CF}_{2}\right)$ \\
759 & 762 & bend. $\left(\mathrm{CF}_{2}\right)+$ bend. $(\mathrm{CCC})$ \\
613 & 612 & bend. $\left(\mathrm{CF}_{2}\right)-$ bend. $(\mathrm{CCC})$ \\
\hline
\end{tabular}

asym asymmetrical, sym symmetrical, str stretching, wag wagging, tw twisting, rock rocking

For the measurements along the sample thickness, the blend becomes a conducting material even for a small amount of PAni $(0.5 \mathrm{vol} \%)$, as can be seen in Fig. 5. This is probably due to the fact that the size of the PAni agglomerate is in the same order of magnitude as the sample thickness. Electrical measurements also allow the analysis of the homogeneity of the films in different places on the sample. In the thickness direction, the blend films show homogeneity, although the measurement along the surface indicates a high PAni concentration in the edges of the films.

Figure 6 shows the behavior of the electrical conductivity when the blend is immersed in an aqueous solution of $0.0001 \mathrm{M} \mathrm{HCl}$ in different volumes, which means different amounts of dopant molecules. To perform this measurement, a 47 vol\% PVDF-PAni blend was immersed in $0.1 \mathrm{M} \mathrm{NH} \mathrm{NH}_{4} \mathrm{OH}$ aqueous solution, becoming an insulator. This occurs because the alkaline solution diffuses through the matrix, dedoping the PAni. The redoping occurs when the sample is immersed in an acid solution, varying the protonation degree according to the $\mathrm{HCl}$ content. A similar study was performed by MacDiarmid [4], where a higher conductivity was observed when immersing the sample in a solution with a lower $\mathrm{pH}$.

Strain-stress tests were conducted in the samples with $0.0,1.0$, and $47 \mathrm{vol} \%$ of PAni. Figure 7 shows the decrease in the deformation capability in the blends with an increasing PAni content; however, with the exception of the conductor phase (1.0 

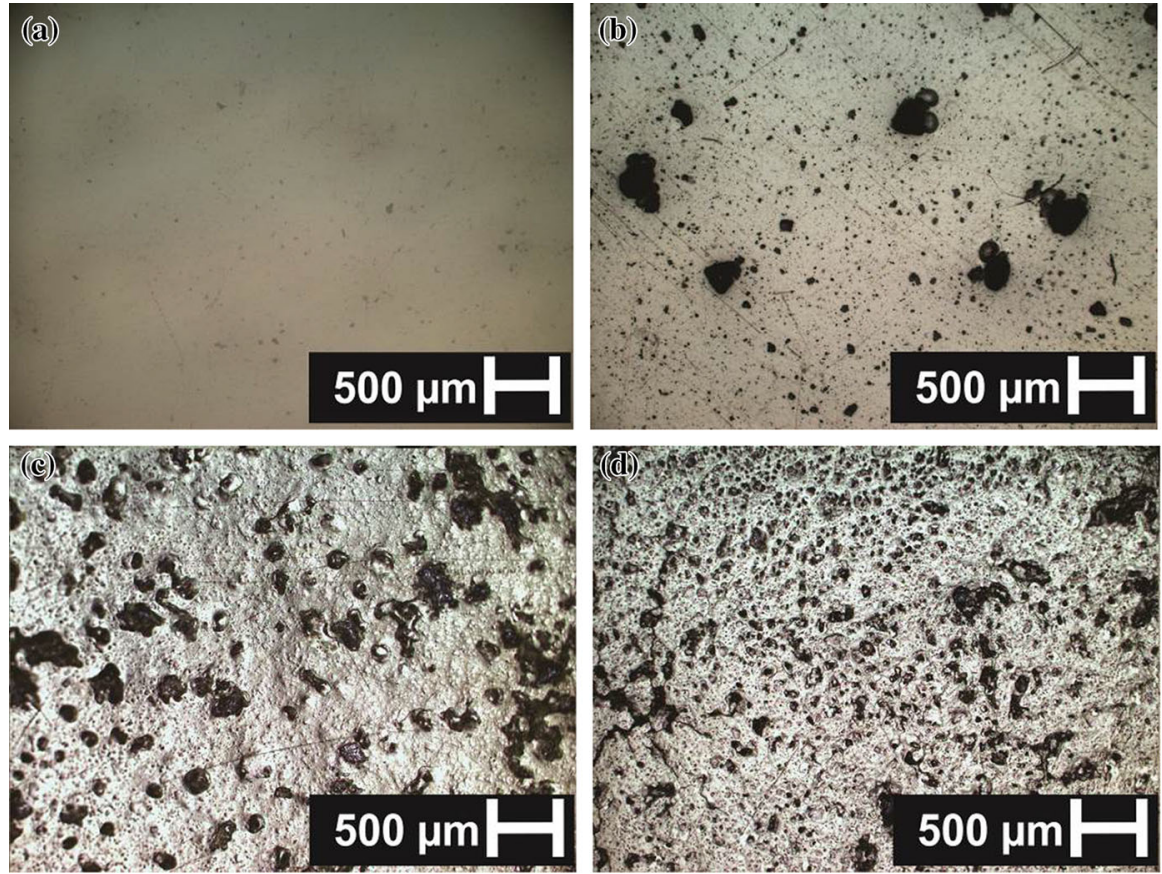

Fig. 2 Optical microscopic images (OM) for samples: a pure PVDF, b PVDF/PAni with a $1 \%$ volumetric fraction of PAni, c PVDF/PAni with a $35 \%$ volumetric fraction of PAni, and d PVDF/PAni with a $47 \%$ volumetric fraction of PAni. The dark part relates to the semiconductor particles and the light part relates to the polymer matrix

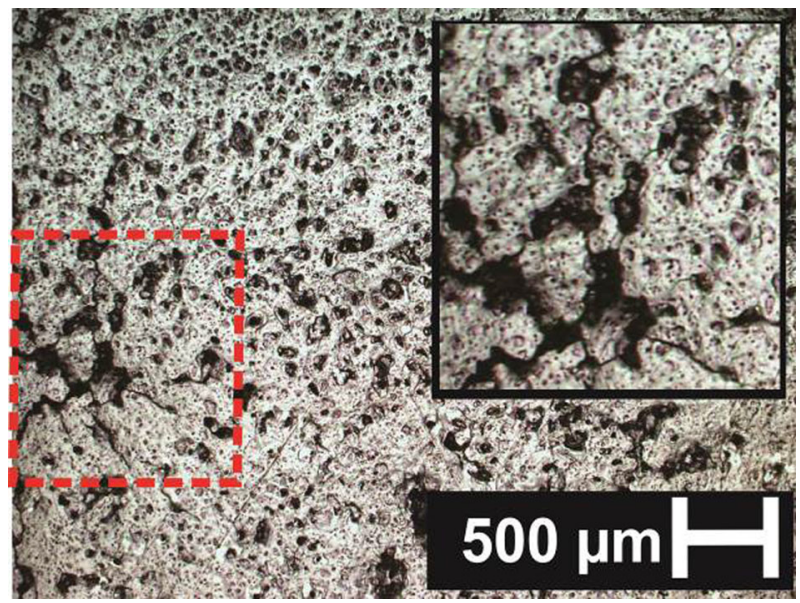

Fig. 3 Microscopic image of PVDF/PAni with $47 \%$ of the PAni in a volumetric fraction

vol\%), the tensile strength increased, indicating the strengthening effect of the inclusions. The slope of the stress-strain curve in the plastic region gives the value of Young's modulus, which specifies the material resistance at low deformation 


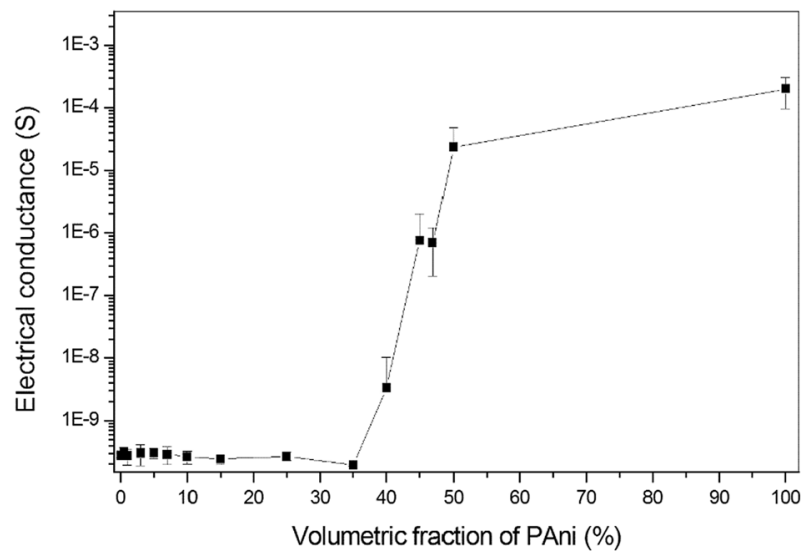

Fig. 4 Electrical conductance of the PVDF/PAni blend films; measurements along the surface

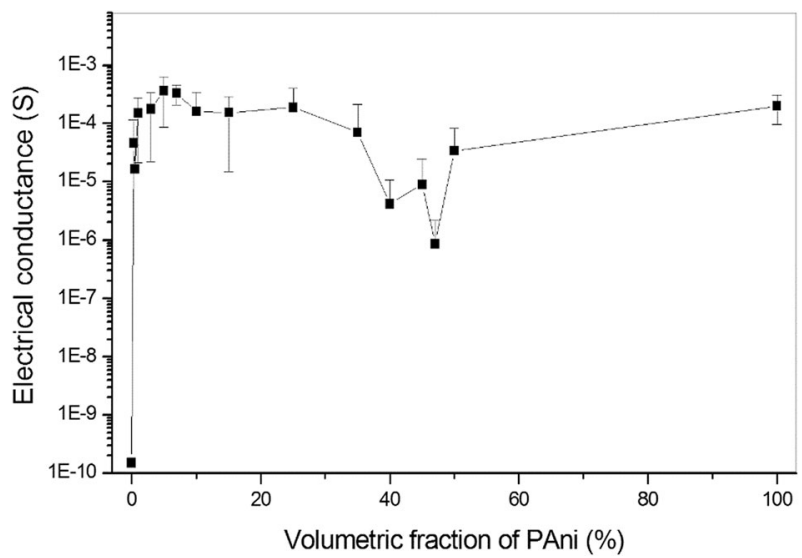

Fig. 5 Electrical conductance of PVDF/PAni blend films; measurements along the sample thickness

[16]. The modulus of the elasticity of pure PVDF is $1.08 \mathrm{GPa}$, while for a blend with $1.0 \mathrm{vol} \%$ it is increased to $1.12 \mathrm{GPa}$, suggesting that the presence of PAni limits the movement of the chains in the polymer matrix [17].

When increasing the PAni concentration, it was observed that the elongation at breaking and elasticity are reduced, probably due to the increased PAni-PVDF interfaces, where physical interactions are fragile [18]. It is worth noting that, if the direction chosen to explore the electrical properties is the thickness direction, the blend with 1.0 vol\% is already percolated, and shows superior mechanical properties, which can be seen in Table 3. The values obtained are similar to those found in the literature. In addition, the low value for the Young's modulus of the pure PVDF can be attributed to the processing of the material, where the material was cooled rapidly to the sudden freezing of the chains and trapping of the PAni particles, to prevent the segregation of phases. In this situation, there was no 


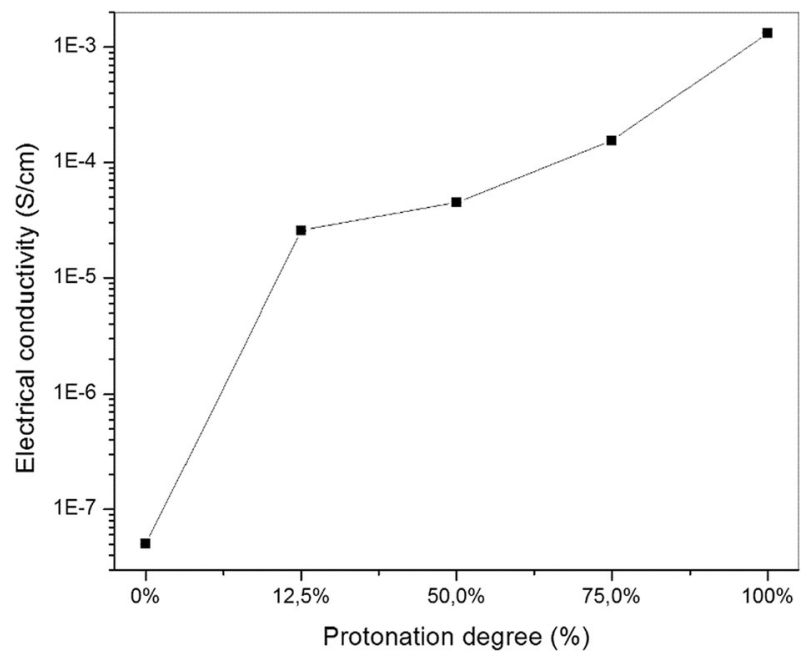

Fig. 6 Electrical conductivity of PVDF/PAni-47\% with different amounts of $\mathrm{HCl}$

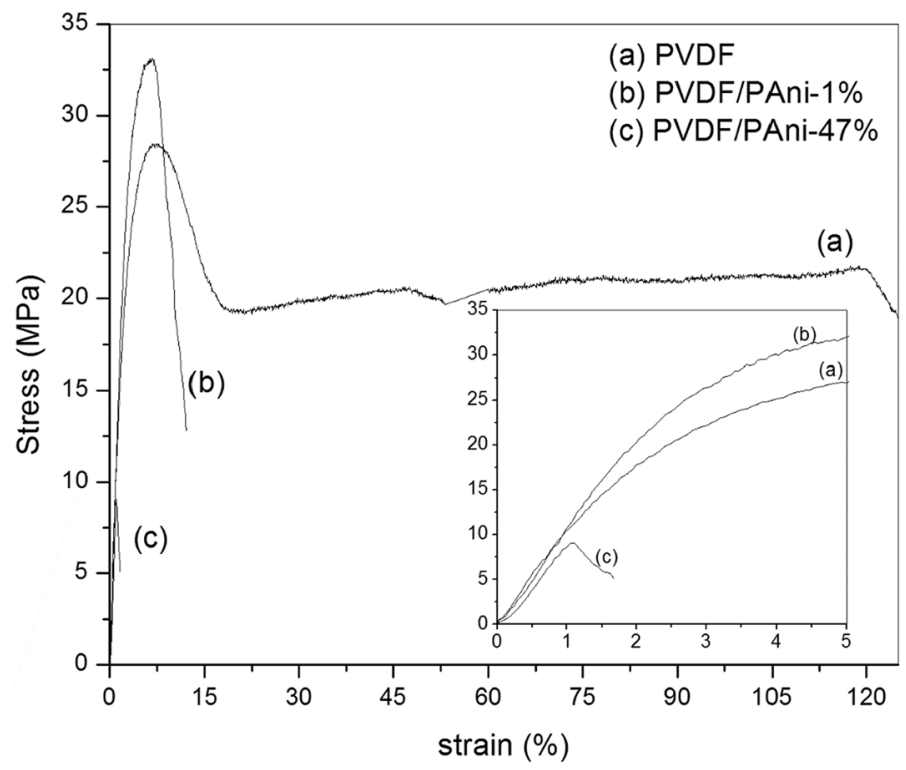

Fig. 7 Stress-strain tests

sufficient time for the recrystallization process to occur efficiently, and the blend was less rigid [5, 6]. However, the material showed a higher breaking strain of around $120 \%$. Only for pure PVDF does a neck begin to form during the stressstrain test. After the maximum stress is sustained by the structure in tension, the deformation is confined to the neck region of the sample. 
Table 3 Results of the stress-strain tests for the pure PVDF and PVDF/PAni blend films, with 1 and $47 \%$ in the volume fraction of the PAni

\begin{tabular}{lllllc}
\hline $\begin{array}{l}\text { Volumetric fraction } \\
\text { of PAni (\%) }\end{array}$ & $\begin{array}{l}\text { Young's } \\
\text { modulus } \\
(\mathrm{GPa})\end{array}$ & $\begin{array}{l}\text { Yield } \\
\text { strength } \\
(\mathrm{MPa})\end{array}$ & $\begin{array}{l}\text { Limit of tensile } \\
\text { strength (MPa) }\end{array}$ & $\begin{array}{l}\text { Rupture } \\
\text { stress (MPa) }\end{array}$ & $\begin{array}{l}\text { Rupture } \\
\text { strain (\%) }\end{array}$ \\
\hline 0 & 1.08 & 10.6 & 28.4 & 21.6 & 120 \\
1 & 1.12 & 10.4 & 33 & 13 & 12 \\
47 & 0.92 & 8.3 & 9.1 & 5.08 & 1.7 \\
\hline
\end{tabular}

Although the blend film with $47 \%$ volumetric fraction of PAni must be a much more fragile material as compared to pure PVDF or PVDF blend with low amount of polyaniline, it is a material with a considerable mechanical resistence when compared to other composites or polymers, such as the case of low-density polyethylene whose Young's modulus and the tensile strength limit are, respectively, 0.17 GPa and 8.3 MPa [19]. Thus, it is a plastic that supports considerable stress and can conduct electricity over their entire surface.

\section{Conclusion}

Free standing films with a PVDF-PAni blend were obtained via the mechanical mixing of the powder of both components, followed by melting the PVDF matrix and then quenching. The resulting material is a two phase blend, since there was no chemical reaction between the components, that is, the blend showed immiscibility.

The percolation threshold was found to be in the range of 40-50 vol\% of PAni along the surface, while only $0.5 \mathrm{vol} \%$ of the PAni was enough for percolation. The blend is $\mathrm{pH}$ sensitive, or more specifically, is sensitive to the amount of dopant molecules $(\mathrm{HCl})$, allowing its use as an electrical device controlling conductivity, as well as a sensor. Moreover, a small amount of PAni in the blend increases the modulus of the elasticity and the tensile strength.

Although the percolation threshold is high, the fragile films are free-standing and have configuration in which included particles are attached to the matrix, but also exposed in some way to the surface, allowing a change of the protonation degree (electrical conductivity) even after the composites are ready.

The blends can be used as $\mathrm{pH}$ sensors, resistors with easily changeable size, shape and resistance, and even capacitors, that can be completely configured (plate and dielectric medium) in one piece, with the interface being defined by the permeability of the solution of protonation.

Acknowledgments The authors express their gratitude to Fundação de Amparo à Pesquisa do Estado de Mato Grosso (FAPEMAT), Fundação de Amparo à Pesquisa de São Paulo-FAPESP (CEPID 2013/07296-2) for financial support. 


\section{References}

1. Strümpler RD, Glatz-Reichenbach J (1999) Conducting polymer composites. J Electroceram 3(4):329-346

2. Wang HL, Fernandez JE (1992) Conducting polymer blends: polypyrrole and poly(vinyl methyl ketone). Macromolecules 25(23):6179-6184

3. Bunde A, Dieterich W (2000) Percolation in composites. J Electroceramics, Dordr 5(2):81-92

4. Macdiarmid AG, Chiang JC, Richter AF (1987) Polyaniline: a new concept in conducting polymers. Synth Met, Lausanne 18(1-3):285-290

5. Lovinger AJ (1982) Developments in crystalline polymers-1. Applied Science Publishers, London, pp 195-273

6. Erdtman E, Satyanarayana KC, Bolton K (2012) Simulation of $\alpha$ - and $\beta$-PVDF melting mechanisms. Polymer 53:2919-2926

7. Nicolas-Debarnot D, Poncin-Epaillard F (2003) Polyaniline as a new sensitive layer for gas sensors. Anal Chim Acta 475:1-15

8. Xiea G, Suna P, Yana X, Dua X, Jianga Y (2010) Fabrication of methane gas sensor by layer-by-layer self-assembly of polyaniline/PdO ultra thin films on quartz crystal microbalance. Sens and Actuators B 145:373-377

9. Mattoso LHC, MacDiarmid AG, Epstein AJ (1994) Controlled synthesis of high molecular weight polyaniline and poly (o-methoxyaniline). Synth Met 68(1):1-11

10. Moulton SE et al (2004) Polymerisation and characterisation of conducting polyaniline nanoparticle dispersions. Curr Appl Phys, Amst 4(4):402-406

11. Abdiryim T, Xiao-Gang Z, Jamal R (2005) Comparative studies of solid-state synthesized polyaniline doped with inorganic acids. Mater Chem Phys, Lausanne 90(2-3):367-372

12. Zulfiqar S, Zulfiqar M, Munir A (1994) Study of the thermal-degradation of polychlorotrifluoroethylene, poly(vinylidene fluoride) and copolymers of chlorotrifluoroethylene and vinylidene fluoride. Polym Degrad Stab, Oxon 43(3):423-430

13. Afzal AB, Akhtar MJ, Ahmad M (2010) Morphological studies of DBSA-doped polyaniline/PVC blends. J Electron Microsc, Tokyo 59(5):339-344

14. Soares BG, Celestino ML, Magioli M, Moreira VX, Khastgir D (2010) Synthesis of conductive adhesives based on epoxy resin and polyaniline. DBSA using the in situ polymerization and physical mixing procedures. Synth Met, Lausanne 160(1):1981-1986

15. Silva MJ, Sanches AO, Malmonge LF, Malmonge JA (2014) Electrical, mechanical, and thermal analysis of natural rubber/polyaniline-Dbsa composite. Mater Resh, São Carlos 17(1):59-63

16. Shaw MT, Macknight WJ (2005) Introduction to polymer viscoelasticity, 3rd edn. Wiley, New Jersey

17. Malmonge LF, Langiano SC, Cordeiro JMM, Mattoso LHC, Malmonge JA (2010) Thermal and mechanical properties of PVDF/PANI Blends. Mater Res 13(4):465-470

18. Fu SY, Feng XQ, Lauke B, Mai YW (2008) Effects of particle size, particle/matrix interface adhesion and particle loading on mechanical properties of particulate-polymer composites. Compos B 39:933-961

19. Callister WD, Rethwisch WG (2010) Materials science and engineering. Wiley, New Jersey 